\title{
Repackaging Louisiana's Crawfish Production and Marketing to Generate Revenue and Employment
}

\author{
Adetutu Alexandra Oseni \\ Southern University and A \& M College, Public Policy Department. \\ Baton Rouge, Louisiana
}

\begin{abstract}
Louisiana accounts for $90 \%$ to $95 \%$ of the total U.S. production of Crawfish from year to year, either from wild waters of the state, or on farms. Even though, the commercial sales of crawfish in Louisiana date back to the late 1800 s - the state is still actively engaged in crawfish industry to provide millions of pounds harvested from farms and natural waterways in the Bayou State. The harvesting of wild crawfish from natural habitats such as bayous, swamps and marshes provides a significant number of jobs for Louisiana residents. The Atchafalaya Basin is world famous for its crawfish production. More than 800 commercial fishermen harvest crawfish from wetlands, mostly in the Atchafalaya Basin. The governor making an attempt to set the favorable environment and also give incentives to the crawfish farmers may boost its production to add to the GDP of the economy. Because revenue generation and employment diversification are very critical to the state of Louisiana, this particular study is devoted to unearth the numerous repackaging techniques for Louisiana crawfish production and its marketing strategies to assist the state in diversifying or broaden its revenue base and employment avenues to ensure growth and development. As a result the study used 200 sample size of crawfish farmers across the state of Louisiana. To better inform policymakers, the study used binomial logistic regression to analyze the perceived determinants of crawfish production in Louisiana. The study found out that the Louisiana State can diversify its marketing strategies to employ more people to work on the promotion of the crawfish production in the state of Louisiana. The following marketing strategies (deployment, channel management, contact database, email marketing, event triggered actions, lead management, multi-campaign and the use of social media platform) revealed in the study to assist the state of Louisiana to improve upon it employment avenues through sales and also expected to generate more revenue for the state through taxes. The study reveals that crawfish farmers continue to be in business due to the following factors: price/profit, government regulations, transport assistance, and the market trends/demand for the product. The study further revealed that repackaging the Louisiana crawfish farming will lead to revenue generation, employment creation, cultural enrichment \& promotion and also improve upon the export earnings associated with crawfish products. Above all, the study strongly recommends that the governors and the federal government should support the repackaging of the old marketing tools used by the farmers to adapt to the modern forms of sales-marketing in order to enhance more jobs creation and also promote the sales of the crawfish products to boost the nation's GDP and revenue generation.
\end{abstract}

Keywords: Employment, Revenue, Crawfish, Logistic Regression, Regulations, Sales, Cultural, and Transport

DOI: $10.7176 / \mathrm{JESD} / 11-12-05$

Publication date:June 30th 2020

\section{INTRODUCTION}

Revenue and job creation are very critical to the nation development and are also major concerns to policymakers. As a result the diversification of employment and revenue generation avenues have become urgent priorities for policymakers in the Louisiana State policy agendas-in order to reduce a growing trade imbalance, unemployment, ensure non-farm job creation, and improve economic growth and development. It is an undeniable fact that goods/commodities productions from both water bodies and terrestrial bodies have become major source for many nations' food security, economic recovery and development tools. In spite of the fact that the State is endowed many natural resources, it is still struggling with funds to finance its developmental projects regarding education and other public utilities. Very surprisingly, Louisiana which has fertile land, endowed with oil, and are also rich in culture as well as agriculture products such as fishing and farming, the state continues to rank dead last in the United States when it comes to education, health care, crime and opportunity for its citizens, according to U.S. News \& World Report's 2019 list of “Best States" (US News \& World Report, 2019). Very importantly, according to the literature, in 2018 the state did not see much changes in the opportunities available for its citizens, as a result the state's development and economic growth rankings continue to decline as observed in 2019. This is so because in 2018 Louisiana ranked 50th among the country's 50 states considered in the ranking, which weighed data on a range of quality of life measures (US News \& World Report, 2019). Unfortunately, Louisiana State fell behind Alabama (49th) and Mississippi (48th) in ranking (US News \& World Report, 2019). As observed in the literature, it has been underscored that the "best state" honor went to Washington, which earned kudos for its booming economy, investment in renewable energy and strong public education. New Hampshire (2nd) and Minnesota (3rd) rounded out the top three. Meanwhile, these states are doing well by playing in their comparative advantages and 
diversifying opportunities for their citizens to which I believe Louisiana and other low ranking states can do same. It seems surprising that Washington, D.C., the Evergreen State's economy ranked No. 1 overall, surpassing Utah, Massachusetts, California and Colorado, respectively (Sheeler, 2019). According to Sheeler (2019), what really worked for them were the innovation potentials that included the share of jobs in high-tech industries, the share of STEM employment and the amount of entrepreneurial activities.

By following the magic of Washington, D.C., Louisiana can trek cautiously to maximize its growth and development to boost its ranking up by applying the concept of innovation potentials or comparative advantage to its crawfish production. Meanwhile, as reported by WeLoveCrawfish.com (2020), Crawfish has only been found in all the southern U.S. states in warm waters during warm weather seasons. To the advantage of the southern states more especially to the State of Louisiana, small harvests of farmed crawfish for human consumption occur in states such as Texas, Arkansas, Mississippi, Alabama and the Carolinas, while Louisiana is by far the largest producer of crawfish in the United States (WeLoveCrawfish.com, 2020). This production sector seems to dominate and maximizes itself in the state of Louisiana. In fact as vividly stated in the literature, crawfish farming has come to stay as a major industry in Louisiana, with Louisiana commercial crawfish farmers providing $85 \%$ of domestically produced crawfish to Louisiana markets and across the nation. The state's annual yield is more than 100 million pounds of crawfish. Louisiana's crawfish farming industry has grown to include more than 1,200 farms occupying more than 120,000 acres. Crawfish ponds have no standard size, but most are between 10 and 40 acres, and most producers manage 150 or fewer acres. Part of diversifying the employment avenues associated with crawfish production, it has been underscored in the literature that some farmers use the crawfish ponds for growing rice at other times of the year, which in effect serves as an irrigation source. In fact, it is an undeniable fact that, Louisiana State can capitalize on this particular employment potentials and avenues to also diversify its revenue generation as well. This is because the State revenue sources has over the years included taxes, licenses, fees, permits, rents and royalties, gaming revenues, interest on investments, proceeds from bond sales, and federal receipts. With the exception of certain self-generated funds, bond proceeds, and federal receipts, these funds are collected by five departments: Revenue, Natural Resources, Treasury, Public Safety and Corrections, and Insurance. Meanwhile, the largest sources of state revenues are individual income taxes and state sales and use taxes, followed by severance taxes. As part of the state's sales the governor can own some state farms made of up crawfish farms to create employment for the youth, can also create a favorable environment for crawfish farmers to entice the youth to engage in crawfish production. In addition to sales revenue from state own crawfish farms, more crawfish workers such as farmers, marketers or sales representatives and export of crawfish implies more tax revenues and more revenue from foreign exchange (or taxes impose on export).

According to statistics, the state of Louisiana is famous in the production and consumption of seafood across the globe. The state has developed a very strong taste for seafood products, in fact as long as a product comes from the water bodies and is suitable for eating, the state finds a way to make it delicious and incomparable. A typical case in point is the Crawfish farming or production in Louisiana (Oluwade \& Adu-Frimpong, 2018). To a large extent, Louisianans will not only eat it but actually make it something others travel to the state just to experiment it. That is, package and branding such product to be more gorgeous to both the internal and external sphere of influence (demand).

Meanwhile, Crawfish as one of the innovative water-bodies products in Louisiana State has gone viral to the utility of both the internal and external sphere of influence. According to the National Geographic Survey (2014), Crawfish is referred to by several names including crawdads, crawfish, river crab, and mudbugs. All these information, speak to the globe how unique crawfish animal production is. For the meantime - paying maximum attention to crawfish production as a form of innovation potentials will diversify the revenue generation and employment creation avenues for both the citizens and the state. As further observed in the literature, by its nature, crawfish can be boiled, baked, or cooked into a delicious meal for both domestic and commercial purposes (Oluwade \& Adu-Frimpong, 2020; Louisiana Crawfish Promotion and Research Board and Louisiana Crawfish Production Manual, 2017). In the state of Louisiana, Crawfish is one of the most versatile foods available and also gain a lot of popularity outside its territory.

Despite, its enormous benefits the state tends to gain from this unique industry, less attention has been given to the production of crawfish and the diversification of the sector to generate more revenue and also support employment creation. This current study tends to examine the diversification of the crawfish production sector in the state of Louisiana. The study will examine the preference of packaging the crawfish product for consumption, importance of crawfish production to revenue generation \& employment, forms of some marketing strategies available to promote the production, and determinants of crawfish production. 


\section{LITERATURE REVIEW SESSION \\ History of Louisiana's Crawfish Production}

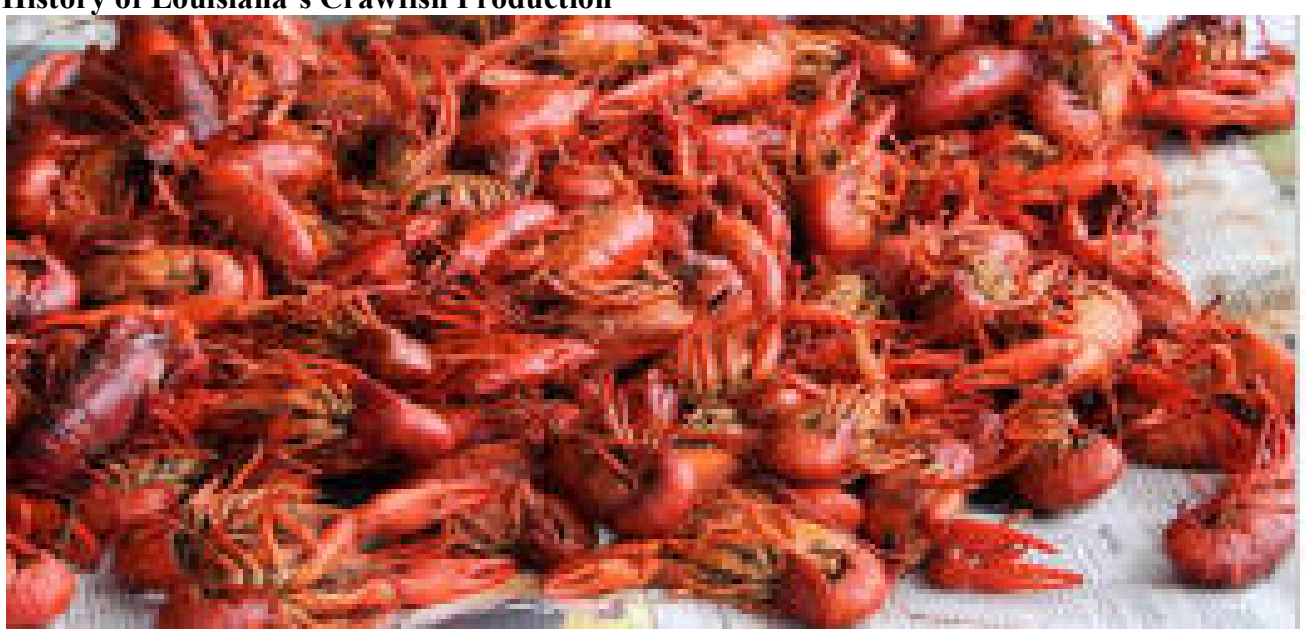

\section{Figure 1: Fresh Water Crawfish Photo}

Crawfish is different from other saltwater fishes/bodies particularly Lobsters which spend their lives in saltwater, including oceans and seas, crawfish set up shelter in fresh water, such as streams, rivers, and ponds. This implies that crawfish production can be expanded easily through artificial inventions. It is based on the assumption of expanding fish production through artificial inventions that the National Fish Hatchery System (NFHS) was established. This system is comprised of a network of field stations located throughout the nation that works with tribal, local, and state governments, other federal agencies, and foreign nations to conserve fisheries. Since the inception of the U.S. Fish and Wildlife Service in 1871, fisheries conservation has figured paramount to people and economies including crawfish as a product or an element of fisheries. Additionally, in 1965, the Fish \& Wildlife Service established seven Fish Technology Centers nationwide to provide science and technology support and guidance to the National Fish Hatchery System and fish culture community. Following the Native Americans and the early European settlers, the crawfish has been and inherent part of Louisiana culture. Abundant in the swamps and marshes across south Louisiana, crawfish were a favorite food of early residents. As part of History, several centuries thereafter, crawfish season in Louisiana is still exciting, with crawfish boils and backyard parties a time-honored tradition. It is very important to note that commercial sales of crawfish in Louisiana began in the late 1800s. At that time, crawfish were harvested from natural waters through- out the southern region of the state. Regarding the crawfish industry in Louisiana, the official nationwide comparisons are not available, but industry experts estimate that Louisiana usually accounts for $90 \%-95 \%$ of the total U.S. production from year to year, either from wild waters of the state, or on farms. Commercial sales of crawfish in Louisiana date back to the late 1800s, and today's crawfish industry includes millions of pounds harvested from farms and natural waterways in the Bayou State. The harvesting of wild crawfish from natural habitats such as bayous, swamps and marshes provides a significant number of jobs for Louisiana residents. The Atchafalaya Basin is world famous for its crawfish production. More than 800 commercial fishermen who harvest crawfish from wetlands, most in the Atchafalaya Basin (Figure 2 for more details), contribute to those totals. 


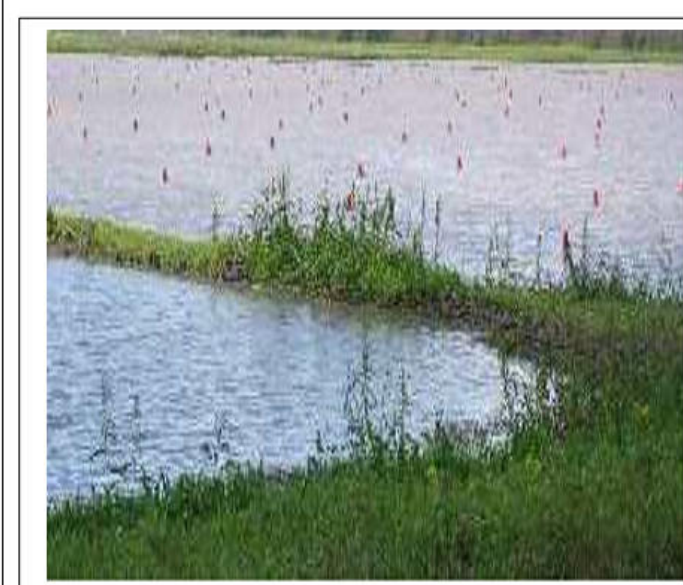

A typical crawfish farm in South Lovisiana

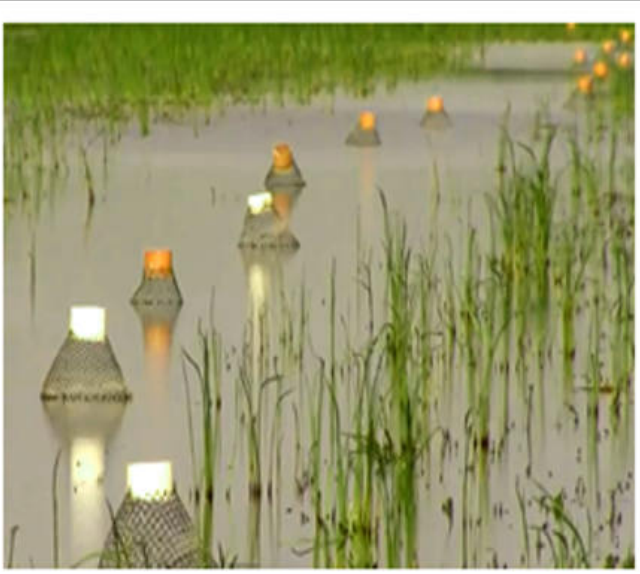

Crawfish traps on a commercial crawfish pond in Louisiana

Figure 2: Pictures of Atchafalaya Basin and Crawfish Traps in Louisiana

Source: Author's Modification of WeLoveCrawfish.com Pictures of Atchafalaya Basin

The industry employs about 7,000 people directly or indirectly and injects $\$ 300$ million into the state's economy each year, according to the Louisiana Crawfish Promotion and Research Board. According to Louisiana Crawfish Promotion and Research Board (LCPRB), during the next 35 years, crawfish farming developed into the largest freshwater crustacean aquaculture industry in the United States. Very importantly, it was underscored that Louisiana leads the nation, producing more than $90 \%$ of the domestic harvest. Below Figure 3 as the nation's map showing the major crawfish states in United States of America:

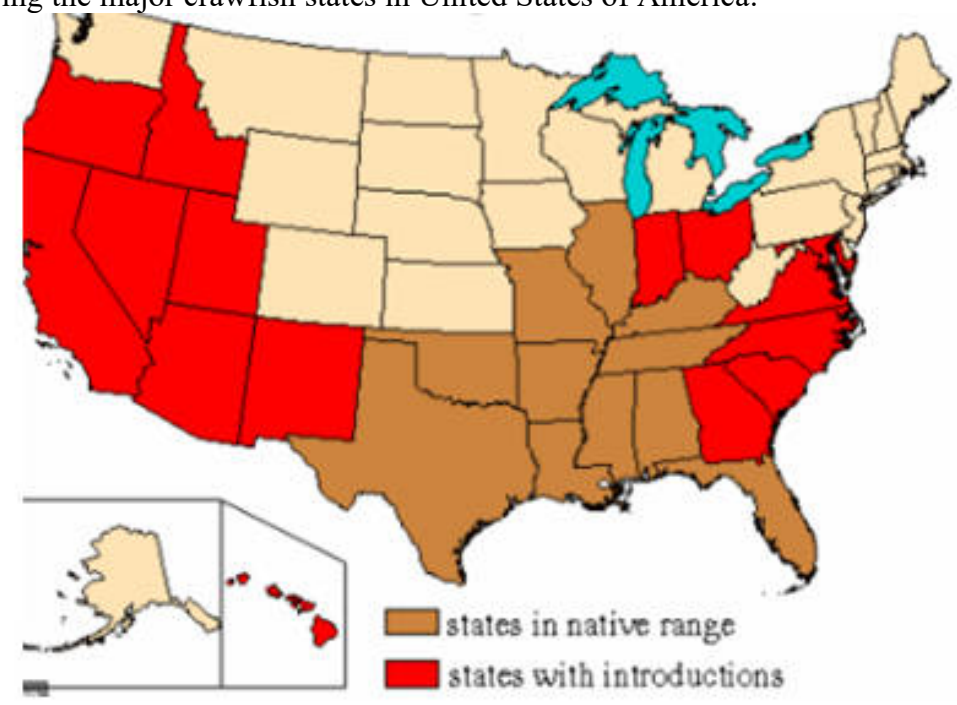

Figure 3: Crawfish Production States [States in native range \& states with introductions] Source: http://www.kern.audubon.org/crayfish.htm

\section{METHOD AND MATERIALS}

This current study is steered by following the Ranganathan et al. (2017) and Robinson (2018) analysis and interpretation of binomial Logistic regression model to estimate the determinants of crawfish production in Louisiana. The variables that have been chosen were selected due to the fact that they adhere to the nominal measurement levels in this particular study. In order to reveal the determinants of crawfish production-the researcher used a binomial logistic regression model to assess the perception of some crawfish farmers in Louisiana. The scope of the subject-matter looked into economic and government policies influences on crawfish production. The study sampled 200 crawfish farmers across different parishes and cities in Louisiana. The estimation of the binomial logistic model follows this equation:

$$
\operatorname{Logit}(Y)=a+B_{1} X_{1}+B_{2} X_{2}+B_{3} X_{3}+B_{4} X_{4} \ldots \ldots+E
$$


For the purposes of this study the Logit(Y) or the dependent variable will be participating in crawfish farming. "a" represents the constant term in the model. "Bs" represents the coefficient of the explanatory variables and the $X$ 's represents the independent variables. $X_{1}=$ Market trends $\{$ If demand influence their production $=1$; if not $=0\}$; $\mathrm{X}_{2}=$ Prices/Pricing package $\{$ If high or favorable crawfish product prices influence their production $=1$; if not $=0\}$; $\mathrm{X}_{3}=$ Regulation \{If favorable government intervention such as subsidies, e.t.c. influence crawfish production $=1$; if not $=0\} ; X_{4}=$ Transport/Near Market Supply \{If transport provision or proximity to market influence crawfish production $=1$; if not $=0\} ; \mathrm{X}_{4}=$ Cultural Enhancement/Enrichment $\{$ If cultural promotion and enrichment influence crawfish production $=1$; if not $=0\}$ and $\mathrm{E}=$ represents the error term in the model. Binomial logistic regression is useful to this study because it is an efficient model when dealing with large datasets with a large sample size. In addition, given that the dependent variable in the study is binary (Yes or No), binomial logistic regression will allow for well-calibrated predictive possibilities (Ranganathan et al., 2017; Robinson, 2018). The study through SPSS 20.0 used p-values computed to determine the statistical significance of the variables estimated. The rejection of the null hypothesis was set at the $5 \%$, significance levels of the Two-tailed test, with a p-critical value of 0.05 .

EMPIRICAL DISCUSSION OF RESULTS

Data Presentations

\section{FORMS OF LOUISIANA'S CRAWFISH PROCESSED FORMS}

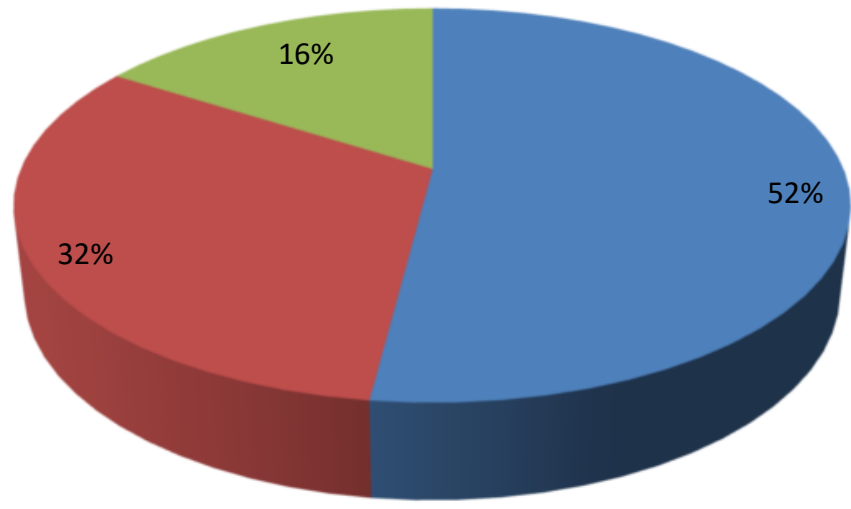

- COOKED

- HAND PICKED

DEVEINED MEAT

Source of Data: Field data, December 2019

Figure 4: Forms of Processed Crawfish in Louisiana

Figure 4 shows the different forms of processed crawfish production in the Louisiana State of United States of America. Figure 4 reveals that about $52 \%$ of the crawfish farmers respondents to the survey preferred cooked form of processed crawfish product, $32 \%$ the crawfish farmers respondents to the survey preferred hand-picked processed forms of crawfish products, while $16 \%$ of the crawfish farmers' respondents to the survey preferred deveined meat form of processed crawfish product. 


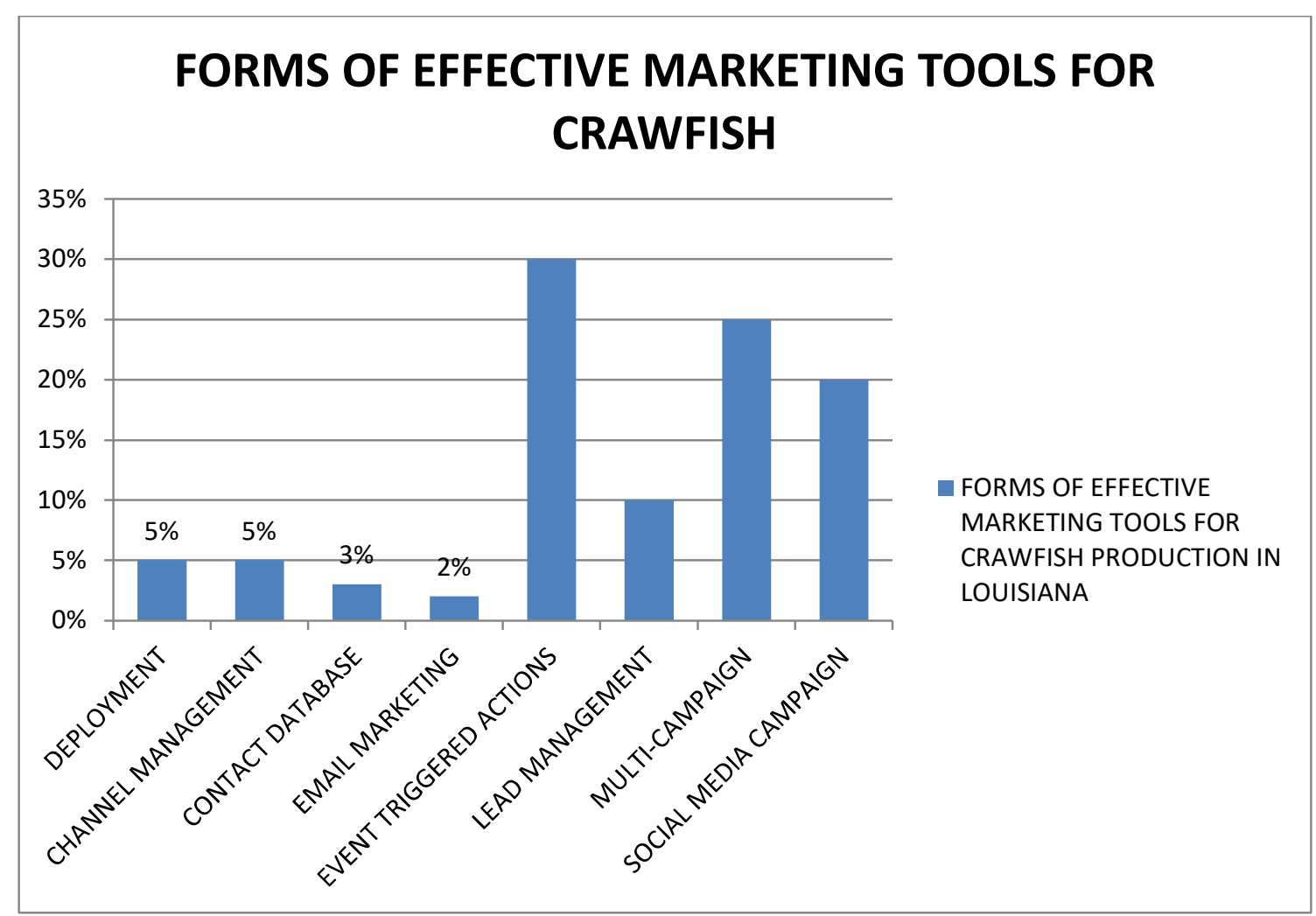

Source of Data: Field data, December 2019

Figure 5: Forms of Effective Marketing Tools for Promoting Crawfish Production in Louisiana

Figure 5 reveals the extent to which Louisiana State can diversify its marketing strategies to employ more people to work on the promotion of the crawfish production in state of Louisiana. It is also expected when more people are employed, they will be taxed to generate more revenue for the state. Figure 5 further reveals that deployment, channel management, contact database, email marketing, event triggered actions (i.e. crawfish festivals \& Mardi Gras), lead management (i.e. branding), multi-campaign (using more of the social media platforms at the sametime Facebook, twitter, instagram, e.t.c. together with either events campaigns or email marketing) and/or using other forms of social media platform at a time such as messenger, zoom, Facebook, twitter and instagram are the various forms to marketing tools that are expected to be effectively implemented to ensure employment and revenue generation diversification to assist the state of Louisiana. This survey is based on the farmers' perception. About $30 \%$ of the farmers from the various production units were of the view that they are likely to utilize the event triggered actions or forms of marketing strategies during periods like Louisiana Crawfish festivals \& Mardi Gras which is celebrated across the parishes, cities and towns within the state of Louisiana. The data further reveal that about $10 \%$ of the farmers were of the opinion that they will using the lead management (i.e. branding) style of marketing to promote the crawfish production in Louisiana. Again, about $25 \%$ of the farmers were of the opinion that they will using the multi-campaign style of marketing whereby sales person uses more than one of the social media platforms at the same time such as adopting Facebook, Twitter, and instagram together with either events campaigns or email marketing to promote the sales of crawfish production in Louisiana. Meanwhile, about $10 \%$ of the farmers were of the opinion that they will using a single social media marketing tool at a specific timeframe before changing to other forms such as either adopting Facebook or Twitter, and/or instagram in order enhance the promotion of the sales of crawfish production in Louisiana. Above all, about $15 \%$ of the farmers were of the view that they will utilize the following marking tools such as deployment, channel management, contact database, and email marketing to promote the sales of crawfish production in Louisiana. 


\section{PERCEIVED DETERMINANTS OF CRAWFISH PRODUCTION IN LOUISIANA}

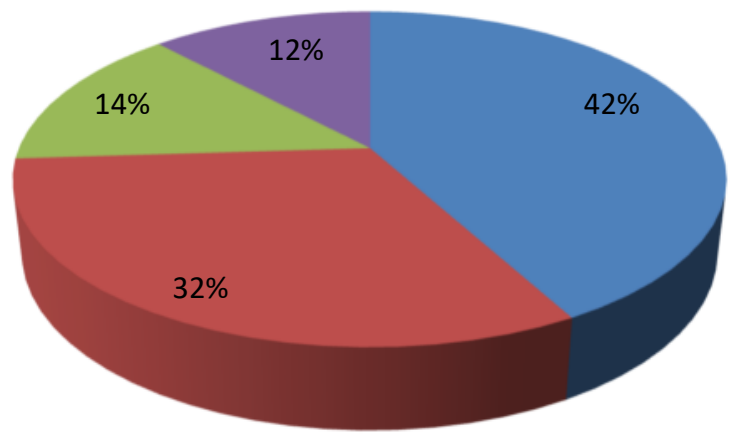

MARKET TRENDS

- PRICES/PRICING PACKAGE

REGULATIONS

TRANSPORT ASSISTANCE

Source of Data: Field data, December 2019

Figure 6: Perceived Determinants of Crawfish Production in Louisiana

Figure 6 make known the perceived determinants of Crawfish production in Louisiana. Very importantly, about $42 \%$ of the farmers were of opinion that marketing trends/or the demand for crawfish products is a crucial factor or determinant to ensure continue production of crawfish in Louisiana. Additionally, $32 \%$ of the farmers were of the opinion that prices/or pricing packages (as a key element to profit) for crawfish products is a crucial factor or determinant to ensure continue production of crawfish in Louisiana. Again, about 14\% of the farmers were of opinion that government regulations (i.e. subsidies or taxes) for crawfish products are crucial factors or determinants to ensure continue production of crawfish in Louisiana. This is because it is expected that government taxes increases production cost and reduces supply and reverse is true. Above all, about $12 \%$ of the farmers were of opinion that proximity to market/or transport assistance for crawfish farmers is also a crucial factor or determinant to ensure continue production of crawfish in Louisiana.

\section{PERCEIVED IMPORTANCE OF CRAWFISH PRODUCTION IN LOUISIANA}

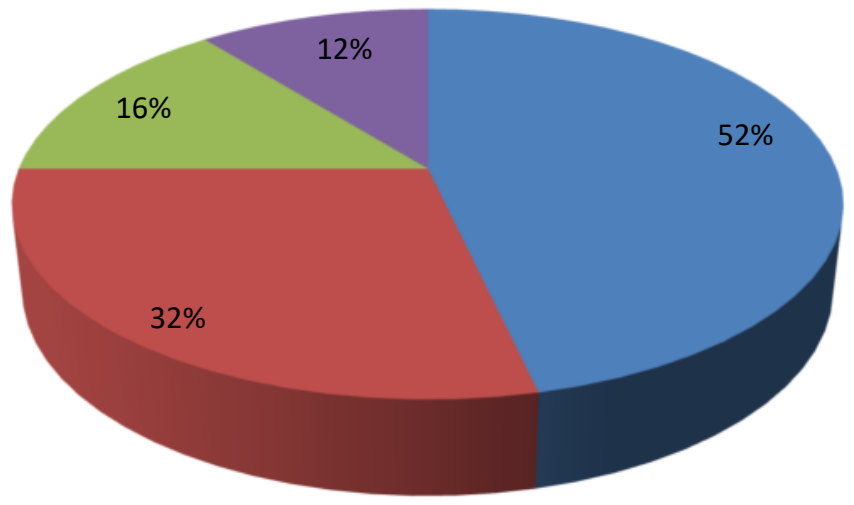

REVENUE GENERATION

EMPLOYMENT CREATION

- CULTURAL ENRICHMENT

EXPORT EARNINGS

Source of Data: Field data, December 2019

Figure 7: Perceived Importance of Crawfish Production in Louisiana

Figure 7 discusses the perceived importance of crawfish production in Louisiana. According to the data, repackaging the Louisiana crawfish farming will lead to revenue generation, employment creation, cultural enrichment \& promotion and improve upon the export earnings associated with crawfish products. Figure 7 shows 
that about $32 \%$ of the respondents were of the view that the diversification or repackaging of the crawfish production will become more attractive to create more jobs to the existing jobs. The data further reveal that about $52 \%$ of the respondents were of the view that the diversification or repackaging of the crawfish production will generate more revenue through sales taxes and income taxes from the crawfish workers. Meanwhile, about $16 \%$ and $12 \%$ of the respondents were of the view that the diversification or repackaging of the crawfish production will enhance cultural enrichment and export earnings, respectively.

Table 1: Binomial Logistic Regression Estimation of the Determinants of Crawfish Production in Louisiana

\begin{tabular}{|c|c|}
\hline Variable & Coefficient \\
\hline Market Trends/Demand & $0.366^{* * *}$ \\
& $(0.000)$ \\
\hline Prices & $0.463^{* * *}$ \\
& $(0.000)$ \\
\hline Regulations & $0.101^{* *}$ \\
& $(0.034)$ \\
\hline Transport & $0.084^{* *}$ \\
& $(0.046)$ \\
\hline R-Square & 0.824 \\
Sample (N) & 200 \\
\hline
\end{tabular}

Note: Standard errors are presented in parentheses. $* * *(* *) *$ denotes significance at $1 \%, 5 \%$ and $10 \%$ significance level respectively.

Source of Data: Field data, December 2019.

Table 1 summarizes the binomial logistic regression estimations of determinants of crawfish production in Louisiana. It was observed from the analysis that the coefficients of the following independent variables such as market trends, prices, government regulations, and transport assistance by governors or policymakers' provision are highly significant. The variables are statistically significant at 5\% and $10 \%$ significance levels because their associated $\mathrm{p}$-values in parenthesis are all less than 0.05 . All the variables also have a positive significant impact or determinants on the zeal for a crawfish farmer to continue in business. This implies that crawfish farmers are more likely to continue crawfish production in Louisiana when the following factors such as market trends, pricing packages, regulations and transport assistance continue to be favorable to the farmers. Above all, among the 200 respondents, about $82.4 \%$ variation in the crawfish production participation is explained by the variations in market trends, pricing packages, government regulations, and transport assistance. Based on the discussion of the field data, the study recommends that (a) the Louisiana government and other key stakeholders should develop policies/regulations that is favorable to crawfish farmers in order to ensure continuity in production to secure the employment avenues for the future generations; and (b) the study further recommends that the governors and the federal government should support the repackaging of the old marketing tools used by the farmers to adapt to the modern forms of sales-marketing in order to enhance more jobs creation and also promotes the sales of the crawfish products to boost the nation's GDP and revenue generation.

\section{References}

Brander K. M. and Easterling, W. (2007). Global fish production and climate change. Pennsylvania State University, University Park, PA. vol. 104 no. 50 , 19709-19714, doi: 10.1073/pnas.0702059104.

Food Agriculture Organization (FAO) of the United Nations, Fisheries Department (2004) The State of World Fisheries and Aquaculture (FAO, Rome).

Louisiana Crawfish Production Manual: Louisiana State University Agricultural Center (www.lsuagcenter.com)LSU AgCenter Publication \# 2637

Louisiana Crawfish Promotion and Research Board. http://www.crawfish.org/history.html

Louisiana Crawfish Promotion and Research Board. http://www.crawfish.org/About.html

Oluwade, B. O. \& Adu-Frimpong, A. (2018). Estimating Louisiana Crawfish Production Function: An Application of Cobb-Douglas Production Function.

Ranganathan, P., Pramesh, C. S., \& Aggarwal, R. (2017). Common pitfalls in statistical analysis: Logistic Regression. Perspectives in Clinical Research, 8(3), 148-151. doi: $1 \quad 0.4103 /$ picr.PICR_87_17

Robinson, N. (2018, June 28). Retrieved from https://www.theclassroom.com/disadvantages-logistic-regression8574447.html

State and Local Government in Louisiana: An Overview 2012-2016 Term. Chapter 2-State Government Functions. https://house.louisiana.gov/slg/PDF/Chapter\%202\%20Part\%20A\%20-

$\% 20$ State $\% 20$ Government $\% 20$ Finance, $\% 20$ State $\% 20$ Revenue $\% 20$ Sources.pdf

Sheeler, A. (2019). Washington has the best economy in the nation, survey says. See how it compares to others.

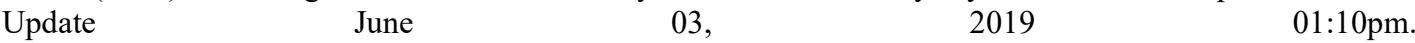
https://www.thenewstribune.com/news/state/washington/article231123068.html 